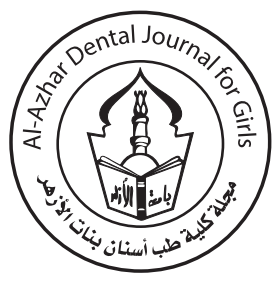

\title{
Evaluation of the Effect of Beverages on Wear Resistance and Microleakage of Class V Esthetic Restorations
}

\author{
Essraa A. Mahmoud ${ }^{(1)}$, Maha A. Niazy $^{(2)}$ and Mohamed A. El Yasaky ${ }^{(3)}$
}

Codex : $37 / 1810$

azhardentj@azhar.edu.eg

http://adjg.journals.ekb.eg

\section{KEYWORDS}

Wear Resistance, Microleak age, Esthetic Restorations.

\begin{abstract}
Aim: This study was carried out to evaluate the effect of beverages (orange juice and cola) on the wear resistance and microleakage of: Self cure Glass Ionomer, Flowable bulk fill composite and Packable bulk fill composite. Materials and Methods: Class $\mathrm{V}$ cavities were preparered on both the buccal and lingual sides, so a total of ninety cavities were created. Teeth were divided into three main groups according to the material used (30specimens each) (A). the first group was restored with the Riva self-cure glass ionomer (A1), the second group was restored by using flowalble bulk fill SDR, Dentsply (A2), while the third group was restored with packable bulk fill composite resin Filtek p 60 (A3). All Each group was further subdivided into three subgroups (Ten specimens each) (B). The specimens of the first subgroup were immersed in an orange juice for 5 minutes, 3x/day over a period of seven days and kept in artificial saliva between erosive cycles (B1). The specimens of the second subgroup were immersed in an acidic cola drink for 5 minutes, 3x/day over a period of seven days and kept in artificial saliva between erosive cycles (B2). The specimens of the third subgroup were immersed in a saline solution for 5 minutes, $3 \mathrm{x} /$ day over a period of seven days and kept in artificial saliva between erosive cycles to be used as control (B3). All specimens were thermocycled $\left(5,00\right.$ cycles, $\left.5^{\circ} \mathrm{C}-55^{\circ} \mathrm{C}\right)$. Results: Regardless to beverage media, it was found that Flowable bulk-fil composite (A2) group had the highest surface profile mean value followed by Packable bulk-fil composite (A3) group meanwhile Selfcure GI (A1) group had the lowest surface profile mean value. Also, irrespective of the material type, totally it was found that Cola (B2) immersed group recorded the highest surface profile mean values followed by Orange juice (B1) immersed group while Saline (B3) immersed group recorded the lowest surface profile mean value. So, it was found that the flowable composite had the highest surface profile roughness, and also the cola had the highest effect on all materials. Regardless to beverage media, totally it was found that Selfcure GI (A1) had the highest leakage score mean value followed by Packable
\end{abstract}

A paper extracted from master thesis entitled "Evaluation of the Effect of Beverages on Wear Resistance and Microleakage of Class V Esthetic Restorations"

1. B.D.S 2009 Faculty of Oral and Dental Medicine Cairo University.

2. Professor of Operative Dentistry \& Head of the Operative Department, Faculty of Dental Medicine, Al-Azhar University (Girls branch).

3. Professor of Operative Dentistry \& Dean of the Faculty of Dental Medicine, Sinai University 
bulk-fil composite (A3) group meanwhile Flowable bulk-fil composite (A2) group had the lowest leakage score mean. Meanwhile irrespective of the material type, it was found that Orange juice (A1) immersed group had the highest leakage score mean values followed by Cola (A2) immersed group while Saline (A3) immersed group had the lowest leakage score mean value.

\section{INTRODUCTION}

With patients now keeping their teeth over their lifetime, there has been an increased challenge to restore Class V cervical carious lesions. The choice of restorative options is often not an easy one to make because the etiology of these lesions affects the durability and clinical success of the restorative materials used ${ }^{(1)}$.

In recent years, increased attention has been placed on the role of carbonated beverages, sports drinks, and their high sugar content in their combined chemical erosive effect on dentin. The habit of drinking many bottles of a national brand carbonated beverage per day, combined with poor oral hygiene, contributed to the presence of anterior Class $\mathrm{V}$ carious lesions. Also Special attention has been given to the citric acid, since it is commonly found in citric fruits and juices ${ }^{(1)}$. Due to its worldwide popularity, orange juice has been considered a suitable representative of citric juices for dental erosion studies ${ }^{(23)}$.

The erosive potential of a citric fruit juice is related to $\mathrm{pH}$ and concentration of the citric acid ${ }^{(4)}$ and the presence of citrate which is a substance capable of chelating the calcium of saliva and teeth ${ }^{(5)}$. These factors are important and can affect the erosive potential of a solution. The bacterial accumulation on the surfaces of restorative materials can provide the bacterial source leading to the development of secondary caries and periodontal diseases. It is highly dependent on the characteristics of the material surface and the roughness of resin composites can influence the oral biofilm adherence ${ }^{(6)}$.

The complex morphology of Class V defects with margins partly in enamel as well as in root dentin presents challenging task for the restorative material. Bond strength and sealing ability of adhesive systems to dentin is still inferior compared to enamel cavity segments. In Class $\mathrm{V}$ the polymerization of composite resins competes with the bond strength of the adhesive systems and challenges marginal integrity and sealing ability especially in dentin segments.

Glass ionomer cements, compomers and resin composites are being mostly used to restore class $\mathrm{V}$ defect. Resin composite combined with dentin bonding systems have already substituted glass ionomer cements and compomers in Class V restorations because of their excellent aesthetics, superior mechanical and physical properties and higher bond strength to enamel and dentin ${ }^{(7)}$.

Despite the improvements of restorative material in recent decades, the marginal integrity of restorations remains a challenge for dentistry. The marginal failure of resin composite restorations is related mainly to the quality of bonding to the dental structures and to stress generated on the restoration. In addition to stress shrinkage, the alterations of the temperature in the oral cavity produce stress on the restoration and can also compromise the marginal sealing ${ }^{(8)}$.

In an attempt to minimize the stresses generated on the interface of the restoration, many restorative materials have emerged in the market. This is possible by modifying some physical and mechanical properties of these materials like Microfilled, Hybrid, Nanofilled, Bulk filled and Packable composites.

Glass ionomers are a unique restorative material. They are self adhesive due to ionic bonding to the tooth structure. Also, glass ionomers are referred to as a "smart" restorative material that not only releases fluoride to the surrounding tooth structure, but also has a semi-permeable surface that allows the calcium and phosphate ions present in saliva to 
pass through the restorative material and combine with the fluoride to produce remineralization of the enamel as a fluorapatite. Another unique characteristic of a glass ionomer is that it provides a high burst of fluoride for remineralization, as well as a prolonged fluoride release over time ${ }^{(9)}$.

\section{MATERIAL AND METHODS}

\section{Preparation of the specimens:}

Teeth selection: Forty-five human freshly extracted sound human premolars were selected for this study. Teeth were extracted for orthodontic reasons from age 14 to 40 . Then they were examined for absence of any carious lesions or cracks, thoroughly washed with water to remove blood and scaled to remove attached periodontal tissues, or calculus using (Cavitron, Dentsply), then stored in saline solution (that was changed every two days) at room temperature to be used within a maximum period of one month.

\section{Sample grouping:}

Class V cavities were prepared on both the buccal and lingual aspects, so a total of ninety cavities were created. Teeth were divided into three main groups according to the material used (30 specimens each) (A). The first group was restored with the self-cure glass ionomer (A1), the second group was restored by using flowalble bulk fill (A2), while the third group was restored with packable bulk fill composite resin (A3). Each group was further subdivided into three subgroups (Ten specimens each) (B). The specimens of the first subgroup were immersed in an orange juice (B1). The specimens of the second subgroup were immersed in an acidic cola drink (B2). The specimens of the third subgroup were immersed in a saline solution (B3) ${ }^{(10)}$. All specimens were thermocycled $(5,00$ cycles, $5^{\circ} \mathrm{C}-55^{\circ} \mathrm{C}$ ) by (Bilge) a Dual chamber water bath machine ${ }^{(11)}$.

\section{Cavity preparation and restoration:}

Class V cavity preparation: Standardized round class V cavities were prepared on both buccal and lingual surfaces of the selected premolars. The cavities were prepared $1 \mathrm{~mm}$ coronal to the cementoenamel junction using round bur size \#023 (Komet, Lemgo, Germany), with high speed hand piece (NSK, Japan) under water coolant $(400,000 \mathrm{rmp})$. The depth of the cavity was $2 \mathrm{~mm}$ and was prepared just by inserting the entire head of the bur, an endodontic file stopper was placed at the termination of the bur head to control the depth. The bur was replaced every 10 preparations. No bevels were made at any of the enamel margins of the prepared cavities. The prepared teeth were stored in saline at room temperature until being used within 1 month ${ }^{(12)}$. Cavities were restored according to the manufactures instructions.

\section{Immersion protocol:}

The specimens of the first subgroup were immersed in an orange juice for 5 minutes, $3 \mathrm{x} /$ day over a period of seven days and kept in artificial saliva between erosive cycles (B1). The specimens of the second subgroup were immersed in an acidic cola drink for 5 minutes, $3 x$ /day over a period of seven days and kept in artificial saliva between erosive cycles (B2). The specimens of the third subgroup were immersed in a saline solution for 5 minutes, $3 x$ /day over a period of seven days and kept in artificial saliva between erosive cycles to be used as control (B3) ${ }^{(13)}$.

\section{Roughness Assement Methodology:}

The optical methods tend to fulfil the need for quantitative characterization of surface topography without contact ${ }^{(14)}$. Specimens were photographed using USB Digital microscope with a built-in camera (Scope Capture Digital Microscope, Guangdong, China) connected with an IBM compatible personal computer using a fixed magnification of 90X.The images were recorded with a resolution of $1280 \times$ 1024 pixels per image. Digital microscope images 
were cropped to $350 \mathrm{x} 400$ pixels using Microsoft office picture manager to specify/standardize area of roughness measurement. The cropped images were analyzed using WSxM software (Ver 5 develop 4.1, Nanotec, Electronica, SL) ${ }^{(15)}$. Within the WSxM software, all limits, sizes, frames and measured parameters are expressed in pixels. Therefore, system calibration was done to convert the pixels into absolute real-world units. Calibration was made by comparing an object of known size (a ruler in this study) with a scale generated by the software. Subsequently, a 3D image of the surface profile of the specimens was created. Three 3D images were collected for each specimen, both in the central area and in the sides at area of $10 \mu \mathrm{m} \times 10 \mu \mathrm{m}$. WSxM software was used to calculate average of heights (Ra) expressed in $\mu \mathrm{m}$, which can be assumed as a reliable indices of surface roughness ${ }^{(16)}$.

\section{Assessment of microleakage:}

The apex of each tooth was sealed by wax and the surface of each tooth (except for $1 \mathrm{~mm}$ around the restoration margin) was covered with two layers of nail polish. Then samples were immersed in a solution of 2\% methylene blue dye (Supreme organization for drugs, Germany) for 24 hours at room temperature ${ }^{(17)}$. Subsequently, the teeth were taken out of the dye solution, washed with water, and the samples were mounted onto special holding device for sectioning. That device is formed of two sides holding the tooth in middle, there is also a screw to customize the size as favored.

The teeth were sectioned facio-lingually with a low speed diamond saw (Top Dent, Edenta Golden, Swiss) under water spray. The specimens were rinsed in running water and then dried with tissue paper. The dye penetration along the cavity wall (including both occlusal and gingival margins) was assessed with a measuring Stereomicroscope (Nikon Eclips E600, Tokyo, Japan) at 45× magnification in which the image of the restoration was captured and transferred to a computer equipped with the image analysis software program (Image J 1.43U,
National Institute of Health, USA), where the leakage was scored as follows ${ }^{(18)}$ :

$0=\quad$ no dye penetration was seen.

$1=$ dye penetration into one third of occlusal or gingival wall.

$2=$ dye penetration into the two thirds of occlusal or gingival wall.

$3=$ penetration of dye along all cavity depth and toward the dental pulp.

\section{Statistical Analysis:}

Data analysis was performed in several steps. Initially, descriptive statistics for each group results. For numerical data (surface profile), two way analysis of variance ANOVA test of significance used for comparing variables affecting mean values (materials, beverages). One-way analysis of variance ANOVA test of significance followed by pair-wise Newman-keuls used for comparing mean values within groups. For catigorical data (leakage scores), three -way analysis of variance ANOVA test of significance used for comparing variables affecting mean values (materials, beverages and location). Non-parametric Kurskal Wallis followed by Dunn's tests was performed to detect significance within groups. Statistical analysis was performed using Graph-Pad Prism-4 software for Windows. $P$ values $\leq 0.05$ are considered to be statistically significant in all tests.

\section{RESULTS}

Regardless to beverage media, it was found that Flowable bulk-fil composite (A2) group had the highest surface profile mean value followed by Packable bulk-fil composite (A3) group. Selfcure GI (A1) group had the lowest surface profile mean value. Also irrespective of the material type, totally it was found that Cola (B2) immersed group recorded the highest surface profile mean values followed by Orange juice (B1) immersed group while Saline (B3) immersed group recorded the lowest 
surface profile mean value. So it was found that the flowable composite had the highest surface profile roughness, and also the cola had the highest effect on all materials. Fig(1)

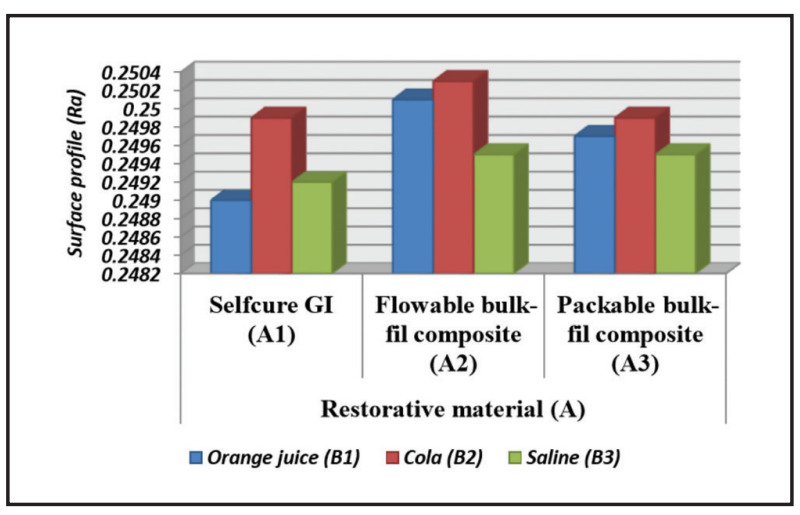

Fig. (1) Histogram of the mean values of surface profile for all materials as function of beverages

Regardless to beverage media, totally it was found that Selfcure GI (A1) had the highest leakage score mean value followed by Packable bulk-fil composite (A3) group meanwhile Flowable bulk-fil composite (A2) group had the lowest leakage score mean. Meanwhile irrespective of the material type, it was found that Orange juice (A1) immersed group had the highest leakage score mean values followed by Cola (A2) immersed group while Saline (A3) immersed group had the lowest leakage score mean value. Fig (2)

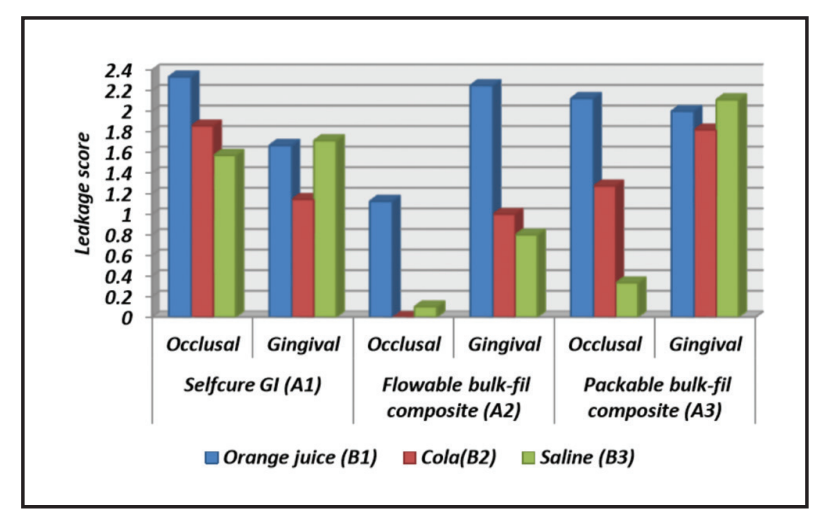

Fig. (2) Histogram of leakage score mean values of for all materials as function of beverages

\section{DISCUSSION}

Satisfactory clinical performance of a restorative material is dependent on its resistance to degradation in the oral environment; among the factors contributing to degradation are abrasion resulting from mastication, attrition, corrosion, erosion, and the effects of oral hygiene procedures ${ }^{(19)}$.

\section{Surface roughness:}

Results of this study revealed that, regardless of the beverage media, Flowable bulk-fil composite (A2) group recorded the statistically significant highest surface profile mean value followed by Packable bulk-fil composite (A3) group meanwhile Selfcure GI (A1) group recorded the statistically significant lowest surface profile mean value. These results are in accordance with a previous study ${ }^{(6)}$ which concluded that acidic and alcoholic drinks eroded the surface of all evaluated flowable resin composites. The type of filler, size and quantity of the particles influence the properties and quality of polishing of restorative materials. The lower the filler loading, the greater the surface degradation and it is well known that the flowable composite has low percentage of filler. However, results are contradicting with another study ${ }^{(13)}$ which concluded that resistance to change in surface roughness of esthetic restorative materials after immersion in cola drink was more in resin based restorative materials as compared to glass ionomer based materials. This could be material related as it compared the glass ionomer to a nanofilled composite, Composites with small filler particles are more homogeneous and their particles are less prominent on the surface, resulting in a lower surface roughness. Whereas, the reduction in space between the inorganic nanoclusters is possibly responsible for superior physical properties of nano-filled composites.

Results of this study denoted that, irrespective of the material type, it was found that Cola (B2) immersed group recorded the highest surface profile mean values followed by Orange juice (B1) immersed group while Saline (A3) immersed group 
recorded the lowest surface profile mean value. The difference between immersion beverage solutions was statistically significant. This agrees with a pervious study ${ }^{(20)}$ which concluded that the consumption of Cola soft drink and coffee alters the microhardness and surface roughness of new restorations. In addition to another study ${ }^{(6)}$ which states that acidic and alcoholic drinks altered the surface roughness of flowable resin composite. Phosphoric acid is a common constituent of most of the soft drinks. Such an acid content is known to play a well established role in the erosive process ${ }^{(21)}$.

\section{Microleakage analysis:}

Results of this study stated that, regardless to beverage media, Selfcure GI (A1) group recorded the statistically significant highest leakage score mean value followed by Packable bulk-fil composite (A3) group meanwhile, Flowable bulk-fil composite (A2) group recorded the statistically significant lowest leakage score mean value. These results are in accordance with a pervious study ${ }^{(22)}$ which concluded that microleakage was evident in all restorative materials, with glass ionomer showing maximum leakage followed by composite resin. This may be due to the slow setting mechanism of conventional GIC (acid-base reaction) which may result in the delay of material adhesion to tooth structure.

The results also denoted that; irrespective of the material type, Orange juice (A1) immersed group recorded the highest leakage score mean values followed by Cola (A2) immersed group while Saline (A3) immersed group recorded the lowest leakage score mean value. These results was on the same line with another study ${ }^{(23)}$ which concluded that fruit juice was found to increase the microleakage for all materials followed by Coca-Cola, tea and coffee, then saline. This could be attributed to the presence of Ascorbic acid and Citric acid that are found in the fruit juice, which is a substance capable of chelating the calcium of saliva and teeth. In acid solutions, $\mathrm{H}+$ ions of citric acid diffused into the glass ionomer components and replaces metal cations in the matrix. These free-cations would diffuse outward and be released from the surface. As the metal cations in the matrix decreased, more would be extracted from the surrounding glass particles causing them to dissolve ${ }^{(24)}$. The influence of the acidity also dissolves the matrix of the resin composite, along with any unstable glass particles in a low $\mathrm{pH}$ value drink. High acidity might have a greater softening effect on the resin matrix, thus promoting the dislodgement and leaching out of filler particles ${ }^{(25)}$. However, these results are inconsistent with a previous study (26) which concluded that cola drink showed the highest microleakage tendency followed by fresh fruit juice (orange) and they related this to the lower PH of the cola (2.49). But regarding acidity strength, it does not only depend on the amount of acid present in the solution ( $\mathrm{H}+$ ion concentration as measured by $\mathrm{pH})$, but also depend on the strength of the acid (ease of dissociation as expressed by the acid dissociation constant, pKa), the buffering capacity (a solution's ability to resist change of its $\mathrm{pH}$ ) and also chelating function of the acid ${ }^{(27)}$. This could account for the highest leakage score mean value recorded by the orange juice as both drinks have varying buffering capacity and/or chelating function.

On comparing the leakage mean value of the tested materials upon immersion in saline (nonacidic - control), it was found that Selfcure GI (A1) group recorded the statistically significant highest leakage score mean value followed by Packable bulk-fil composite (A3) group. Meanwhile Flowable bulk-fil composite (A2) group recorded statistically significant lowest leakage score mean value, when immersed in saline. At the same time the results showed that after immersion in both acidic beverages (cola, orange), the Packable bulk-fil composite (A3) group recorded the statistically significant highest leakage score mean value followed by Selfcure GI (A1) group. While Flowable bulk-fil composite (A2) group recorded the statistically significant lowest leakage score mean value. These re- 
sults are in accordance with another study ${ }^{(28)}$ which discussed the surface microhardness and marginal integrity of restorative materials after immersing them in a cola soft drink for variable periods of time. It concluded that the marginal integrity of all materials was affected by immersion in cola under high immersion time. Moreover, another study ${ }^{(29)}$ stated that the chemical in Cola soft drinks affected the integrity of the enamel surface and that Cola removed much of the sealant along with the enamel. It is clear that the higher microleakage scores seen in the present study could be due to much of the restorative materials being removed along with the enamel when immersed in cola.

As general, results demonstrated that the gingival site recorded higher microlekage score than occlusal site regardless of the other factors. These results are in accordance with another study ${ }^{\left({ }^{(3)}\right)}$ which evaluated the microleakage in class $\mathrm{v}$ composite restorations. It is well known that bonding to enamel is a relatively simple process, without major clinical requirements or difficulties. The presence of enamel at the occlusal margin of cavities makes a suitable bonding in this region, but bonding to dentin on the other hand, presents a much greater challenge and has proved to be more problematic than enamel for a number of reasons including presence of water in dentin and many variations in the substrate ${ }^{(31)}$.

\section{CONCLUSION}

Under the conditions of this study, the following could be derived; None of the tested materials can completely eliminate microleakage at both occlusal and gingival margins. Wear resistance and microleakage of class $\mathrm{V}$ esthetic restorations are material dependent. Surface roughness of some class V esthetic restorations is highly affected by beverages being greater with higher acidity. Although increasing the flowability of the resin composite improves the sealing ability of the restoration, yet it negatively affected the wear resistance of the esthetic resin restoration.

\section{REFERENCES}

1. Voronets $\mathbf{J}$ and Lussi A. Thickness of softened human enamel removed by toothbrush abrasion: an in vitro study. Clin Oral Invest 2010; 14:251-256.

2. West NX, Maxwell A, Hughes JA, Parker DM, Newcombe RG and Addy M. A method to measure clinical erosion: The effect of orange juice consumption on erosion of enamel. J Dent. 1998; 26:329-335.

3. Lussi A and Jaeggi T. Chemical Factors. Mon Oral Sci 2006; 20:77-87.

4. Meurman JH, Rytomaa I, Kari K, Laakso T and Murtomaa $\mathrm{H}$. Salivary $\mathrm{pH}$ and glucose after consuming various beverages, including sugar-containing drinks. Caries Res $1987 ; 21: 353-359$.

5. Tyas MJ. The class V lesion: aetiology and restoration. Poggio C, Chiesa M, Dagna A, Colombo M and Scribante A. Surface roughness of flowable resin composites eroded by acidic and alcoholic drinks. J Conserv Dent 2012 15:137-40.

6. Poggio C, Chiesa M, Dagna A, Colombo M and Scribante A. Microleakage in class $\mathrm{V}$ gingiva-shaded composite resin restorations. Ann Stomatol (Roma) 2012; 3: 19-23.

7. Martins LR. Marginal adaptation of class V composite restorations submitted to thermal and mechanical cycling, J. Appl. Oral Sci. 2013; 21:18-24

8. $\mathrm{Xu} \mathrm{X}$ and Burgess JO. Compressive strength, fluoride release and recharge of fluoride-releasing materials. Biomaterials 2003; 24:2451-2461.

9. Visser HJ, Brandt PD and de Wet FA. Fracture strength of cuspreplacing fibre-strengthened composite restorations. S. Afr. dent. j. 2014; 69:380-392.

10. Francisconi LF, Honório HM, Rios D, Magalhães AC, Machado MA and Buzalaf MA. Effect of erosive $\mathrm{pH}$ cycling on different restorative materials and on enamel restored with these materials. Operative Dentistry 2008; 33:203-208.

11. Bagheri $\mathbf{M}$ and Ghavamnasiri $M$. Effect of cavosurface margin configuration of Class $\mathrm{V}$ cavity preparations on microleakage of composite resin restorations. J Contemp Dent Pract. 2008; 9:122-129.

12. Bajwa NK and Pathak A. Change in Surface Roughness of Esthetic Restorative Materials after Exposure to Different Immersion Regimes in a Cola Drink. ISRN Dentistry 2014: 6:188-201. 
13. Abouelatta O. 3D Surface Roughness Measurement Using a Light Sectioning Vision System. Proceedings of the World Congress on Engineering 2010; 1:23-34.

14. Horcas I, Fernández R, Gómez-Rodríguez J, Colchero $\mathrm{J}$, GómezHerrero $\mathrm{J}$ and Baro A. Review of Scientific Instruments 2007; 78:289-298.

15. Kakaboura A, Fragouli M, Rahiotis C and Silikas N. Evaluation of surface characteristics of dental composites using profilometry, scanning electron, atomic force microscopy and gloss-meter. J Mater Sci Mater Med 2007; 18:155-63.

16. Souza E, Pappen F, Shemesh H, Estrela C and Filh I. Reliability of assessing dye penetration along root canal fillings using methylene blue. Aust Endod J 2009; 2:1747-4477.

17. AL-Azzawi H, AL-Hyali $\mathrm{N}$ and Al-Dabbagh $\mathrm{F}$. Microleakage of class II packable resin composite lined with flowable composite and resin modified glass ionomer cement. J Bagh College Dentistry 2012; 24:65-76.

18. Santos GB, Alto RV, Filho HR, da Silva EM and Fellows CE. Light transmission on dental resin composites. Dent Mater 2008 May; 24:571-576.

19. Silva M, Fardin A, Vasconcellos R, Santos L, Tonholo J, Júnior J and Reis J. Analysis of Roughness and Surface Hardness of a Dental Composite Using Atomic Force Microscopy and Microhardness Testing. Microscopy and Microanalysis 2011; 17:446-451.

20. Maganur, Prabha Devi C. Prabhakar, A. R. Sugandhan, S.Namineni, and Srinivas. Evaluation of microleakage of RMGIC and flowable composite immersed in soft drink and fresh fruit juice. Int J Clin Pediatr Dent. 2010; 3:153-161.

21. Mali P, Deshpande S and Singh A. Microleakage of restorative materials: An in vitro study. J Indian Soc Pedod Prev Dent 2006; 24:15-8.
22. Dinakaran S. Evaluation of the effect of different food media on the marginal integrity of Class V compomer, conventional and resinmodified glass-ionomer restorations: An in vitro study. J Int Oral Health 2015; 7:53-58.

23. Fukazawa M, Matsuya S and Yamane M. Mechanism for erosion of glass ionomer cements in an acidic buffer solution. J Dent Res. 1987; 66:1770-1774.

24. Erdemir U, Yildiz E, Eren MM and Ozel S. Surface hardness of different restorative materials after long-term immersion in sports and energy drinks. Dent Mater $\mathrm{J}$. 2012; 31:729-36.

25. Maganur P, Prabhakar A, Satish V, Namineni S, Kurthukoti A. Erosive Effect of Soft Drink and Fresh Fruit Juice on Restorative Materials. World Journal of Dentistry, JanuaryMarch 2013; 4:32-40.

26. Bamisea CT, Kolawolb KA and Oloyedec EO. The Determinants and Control of Soft Drinks-Incited Dental Erosion. Clín. Pesq. Odontol 2009; 5:141-154.

27. Vanga V. Narsimha. Effect of Cola on Surface Microhardness and Marginal Integrity of Resin Modified Glass Ionomer and Compomer Restoration. People's Journal of Scientific Research 2011; 4:34-40.

28. Steffen JM. The effects of soft drinks on etched and sealed enamel. The Angle Orthodontist 1996; 66:449- 456.

29. Sooraparaju SG, Kanumuru PK, Nujella SK, Konda KR, Reddy KB, Penigalapati S. A comparative evaluation of microleakage in class $\mathrm{v}$ composite restorations. Int J Dent. 2014; 2:66-72.

30. Moezyzadeh M. and Kazemipoor M. Effect of Different Placement Techniques on Microleakage of Class V Composite Restorations. Journal of Dentistry, Tehran University of Medical Sciences 2009; 6:121-129. 